\title{
AN INTERVIEW WITH DR. MOHAMMAD ISMATH RAMZY MOHAMMAD ISMAIL
}

\section{Interviewed by: Ulviyye AYDIN}

\author{
iD : https://orcid.org/0000-0002-6713-5917 \\ Manisa Jalal Bayer University, Turkey \\ International Multicultural Network Country Representative in Turkey
}

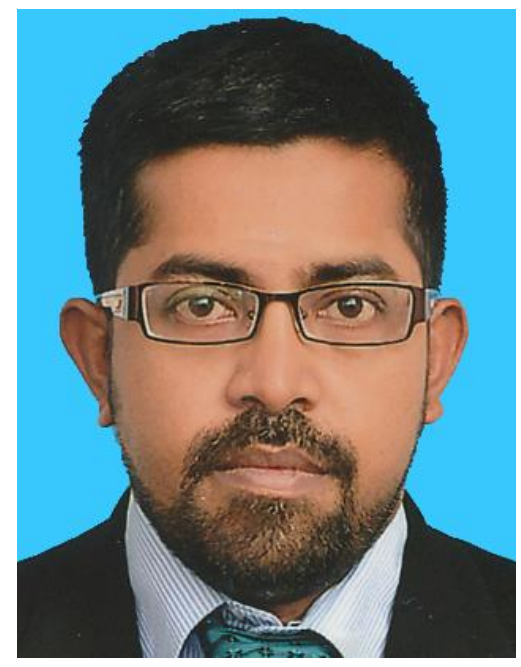

Our guest is Dr.Mohammad Ismath Ramzy Mohammad Ismail, Senior Lecturer, Department of Educational Foundations and Humanities, Faculty of Education, University of Malaya, W.Persekutuan Kuala Lumpur, Malaysia. He teaches courses in sociology of education and actively involved in Peace Education and religious dialogue, mainly Muslim-Buddhist. His interest includes Intercultural Education, multiculturalism, sociology of education, diversity and social cohesion. He is a recipient of Vienna KAICIID fellowship and currently, and involves in researches like "Social Cohesion through tertiary education", "Effective Teaching \& Learning in Malaysian Primary Schools" and "Towards Progressive Society, Capacity for Peace" and Interfaith Dialogue between Muslims and Buddhists. He has published research articles in International Review Journals including ISI and Scopus. Also has written several book chapters including 07 entries to the Encyclopedia of Indian Religions published by Springer.

(C) 2021.All rights reserved. 


\section{UA: Welcome, Dr. Mohammad Ismath Ramzy Mohammad Ismail. Let's jump right in. What is intercultural competence?}

MIR: Intercultural competence (IC) is a term subject to a variety of interpretations and terminologies. Intercultural effectiveness, intercultural communication competence, transcultural communication competence, intercultural action competence are some of the popular terms that communicate Intercultural competence.

Although many scholars have defined Intercultural competence, Deardorff (2008) definition is distinctive. He defined it "the ability to communicate effectively and appropriately in intercultural situations based on one's intercultural knowledge, skills, and attitudes" (p. 33). In this definition, Deardorff has explained Intercultural Competence as an ability to interact with people in a multicultural environment. However, intercultural competency is not only an ability to interact with people positively without hurting anyone but also is a skill that avoids misunderstanding. Hence, it can be defined as "set of cognitive, affective, and behavioural skills that support effective and appropriate interaction in a variety of cultural contexts." It is not just sharing same culture or having attitudes among a similar background of people, rather it is an ability to understand people with different culture and to interact with them without disturbing their cultural, religious, and emotional attachments and commitments.

\section{UA: Which elements of intercultural communication competence should} be used?

MIR: In addition to formal face to face discussion, meetings, technologyassisted methods of communication such as chatroom, forum, assignments, whatsapp, interactive videos, quiz, cross-culture assignments are some technologies that could be used to enhance IC among students.

\section{UA: How can we measure pragmatic and intercultural competences?}

MIR: There are many models to measure Intercultural Competence such as the Intercultural Interlocutor Competence of Fantini (1995), the Intercultural Competence of Byram (1997), Intercultural Maturity of King and Baxter Magolda (2005), the U Curve Hypothesis model of Lysgaard's (1995), the extended W Model of Acculturation and Re-acculturation of Gullahorn and Gullahorn (1963), and the Developmental Model of Intercultural Sensitivity (DMIS) of Bennett (1993). However, the process model of Intercultural Competence (PMIC) of 
Deardorff's $(2006,2009)$ seems to me more comprehensive. It is because, this model captures any initiative of intercultural competence as it is considered Intercultural Competence as a lifelong process moving through four stages namely; (i) begins with the attitude of openness, curiosity, and respect, (ii) then leads to knowledge, (iii) a change in perspective, and finally (iv) a change in actions.

\section{UA: How can instructors assess the intercultural competence of their students?}

MIR: Intercultural Competence of students can be assessed based on their self-efficacy, tolerance of ambiguity, critical thinking and creativity, openness and flexibility, knowledge of one's own culture, and respecting others' culture.

\section{UA: What guidelines should be taken into account in order to develop the Intercultural Competence in university students?}

MIR: Yes, to increase Intercultural Competence among University students, there should be a multicultural environment in the institution. Having students with different cultural and religious background in an institution alone will not help to develop Intercultural Competence. There should be courses to interact each other. Further, teachers have to play a role in increasing interactive opportunities. For this purpose, teachers have to introduce pedagogical strategies such journal write-up, discussion, video presentation, assignment, Group presentations, face to face lecture, and journal article review as well as other methods to increase meeting each other and discuss. These meetings will break the gaps among students and provide options to share each other. This will lead to develop trust among them and to involve in dialogue on cultural and religious differences.

\section{UA: What is the effectiveness of value education in the post-conflict reconciliation process?}

MIR: Yes, value education is very important in reconciliation process in a multi-ethnic and multicultural society. It is because, value education motivates students to value theirs as well as others' culture in the interest of long-term wellbeing of all (Robb, 1998). Value education is a system of education that cumulate the process of a person's positive values that develop from his or her abilities, attitudes and behaviors in a society. As far as positive perception and emotional attachment are essential to reconciliation process, value education play an important role in promoting social cohesion. For this reason, Malaysian Blue 
Print 2015-2025 aims at producing Malaysian citizen who internalize values based on God ensuring physical, intellectual, emotional and spiritual well-beings. Malaysian Blue Print 2015-2025 defines, ,well-grounded individuals' as the individuals who maintain "the balance between both knowledge and skills (ilmu) as well as ethics and morality (akhlak)". Hence, value eduction is necessary to promote social unity.

\section{UA: Can you tell us an effective way to measure ethics learning?}

MIR: The interaction between teacher and student is the primary measure of a smooth function of learning. It is because, teacher-student interaction helps to achieve (a) learning outcomes (b) contextualization of students' knowledge and skills (c) connection the resources with learners and teachers, and (d) connection with teaching or learning activity. Hence, interaction is the basic measure to evaluate learning occurrence.

\section{UA: Is Intercultural competence essential for democratic culture \& social cohesion?}

MIR: Yes, intercultural competence is essential to promote democratic culture and social cohesion. It is because, intercultural competence promotes students' self-efficacy, tolerance of ambiguity, critical thinking and creativity, openness and flexibility, knowledge of one's own culture, and respecting others' culture.

\section{UA: Can cultural values act as norms?}

MIR: Values are moral principles derived from your culture while social norms are the informal rules to ensure group coherence. The Norms are explicit statements on how people should behave in a certain situation in a given social group. The legal provisions are formal norms while instrumental cultural values are informal norms. Social norms determine the survival of a group in a social setting. In sociology, cultural values are generally considered as abstract principles for action, while cultural norms are seen as specific guide for people's behavior. Hence, cultural values of a certain group cannot act as norms. 


\section{UA: What is cultural particularism?}

MIR: The cultural particularism means a specific culture in a multicultural society. Since a culture is a product of a group of people, it shapes their worldview and the way they live. It means the culture is a unique product of a unique selection, transformation and appropriation of a certain set of characteristics, that in reverse shapes minds of those who belong to a certain culture. Although outsider of this culture can access this culture and understand, the structure and process of transformation is incomprehensible as cultures are unique in structure based on its own inner logic. Hence, every culture has its unique moral system, worldview as well as way of progress. For an outsider, it is not only difficult to understand properly but also create sometime misunderstandings. This is cultural particularism. (further reading: Zygadło, P. (2018). Cultural Particularism and Intercultural Communication: The Case of Chinese Face. IAFOR Journal of Cultural Studies, 3(2), 65-77.)

\section{UA: What about the cultural diversity of declared values, and their contradictory co-existence?}

MIR: Although each culture has its value system and particular worldview, all these cultures have some common elements such as love, justice, truth and etc. This aspect is the key to promote co-existence and social coherence.

\section{UA: Does any scientific evidence exist about the alleged benefits of multiculturalism and extreme diversity?}

MIR: Since multiculturalism is the product of Western societies, it aims a social cohesion on the basis of secular values. It means, multiculturalism sees religious and cultural consciousness as challenge to social cohesion as reflected in Huntington theory of clash of civilization. Hence social cohesion, according to multiculturalism, is possible in a society that ignore religious and cultural values. However, Eastern societies have proved amicable relationship and social cohesion based on religious values in the history. Sri Lanka is a multiracial country for instance, has record no any racial issue until 1850 and Sinhalese, Tamils and Muslims were living together for more than thousand years. Lorna Dewaraja in her book "the Muslims of Sri Lanka-One thousand years of ethnic harmony (9001915) as well as Ven. Walpola Rahula in his book ,the Heritage of the Bhikkhus' have portrayed social harmony in Sri Lanka under the ruling of Singhala Buddhist kings. I strongly believe that the differences of religion and culture are not the root cause of violence among different religious communities although the 
involvement of some religious leaders is prevalent in this violence. The political interest exploits the religions.

UA: The role of religion in developing ethics.......

MIR: The religions play a vital role in developing ethics. It is because religion provides worldview as well as end-goal. The ethics that build upon religious belief is stronger than the ethic build upon secular foundation. It is because, religious values ideally create double layer responsibility in referring to God consciousness; responsibility towards the system or administration as well as responsibility towards God. For instance, a Muslim supposed to speak and practice truth everywhere and all times. As a lecturer in a university, a Muslim has to treat students fairly as it requires by the institution. In the same time, he or she has to treat students fairly as he or she is responsible for this treatment to the God. Hence, religion can play a vital role in developing ethics.

\section{UA: Is Islamic insurance an alternative to conventional insurance?}

MIR: Upto my knowledge, Islamic insurance is a developing system and not fully developed yet. Hence, it takes time to replace conventional insurance.

I sincerely thank Dr.Mohammad Ismath Ramzy Mohammad Ismail for sharing your opinions and experiences with the audience of the International Journal of Multiculturalism. Thank you for the opportunity to interview.

MIR: Thank you. 